two summers with survival of a good spatfall. The New Brighton material has considerable scientific value and will be discussed along with that of greater value from Morecambe Bay in detail in the future.

L. E. BUntrng.

A. EsLick.

J. W. JoNES.

J. H. ORTON.

Department of Zoology,

University of Liverpool. March 9.

1 J. H. Orton, Mar. Biol. Assoc., 14, 251 (1926).

2 J. H. Orton, Superintendent's Report, Lancs. and Western S.F.C. March, 1935.

J. H. Orton, James Johnstone Memorial Volume, Liverpool, p. 97, 1934 .

\section{Number of Chlorophyll Molecules acting as an Absorbing Unit in Photosynthesis}

Is view of Gaffron and Wohl's ${ }^{1}$ general discussion of the photosynthetic mechanism of the green plant, the following unpublished, supporting experiment, carried out last spring at Harvard by W. A. Arnold and $m e$, is of interest.

We measured manometrically the photosynthesis (oxygen produced) per flash of light by a thin suspension of the green alga Chlorella pyrenoidosa ${ }^{2}$; source, neon discharge tube; spectral region 6250 6950 A. ; l flash $=10^{-4}$ sec.; 15 flashes per sec. Thus the Blackman (temperature sensitive) reaction was eliminated ${ }^{2}$, the mean lifetime of which at $23.5^{\circ} \mathrm{C}$. is $0.02 \mathrm{sec}$.; also, carbon dioxide was not a limiting factor. Assuming the average quantum to correspond to $6500 \mathrm{~A}$., we studied the yield per flash as a function of quanta per flash.

(1) At 99 per cent light saturation, not more than 1 in 100 chlorophyll molecules absorbed 1 quantum per flash, that is, the probability of an absorption is $10^{-2}$. The probability of four consecutive absorptions by one chlorophyll molecule is therefore $\left(10^{-2}\right)^{4}=10^{-8}$. If we assume that four consecutive absorptions are necessary to reduce one molecule of carbon dioxide, then, since there were circa $10^{16}$ chlorophyll molecules present, it should have taken a minimum of one year to produce I c.mm. of oxygen under the conditions of our experiments*. Therefore, since four quanta are necessary $^{8}$ to reduce one molecule of carbon dioxide, we must postulate the existence of a mechanism which can reduce a particular carbon dioxide molecule with quanta absorbed by different chlorophyll molecules.

(2) Let $M$ be the fraction of the maximum photosynthesis per flash, obtained at the energy per flash $E$ (in quanta per $\mathrm{cm} \cdot{ }^{2}$ ). Experimentally we found

$$
\log _{e}(1-M)=-A \times E \text {. }
$$

Regarding this expression from the number of quanta to kill type of analysis 4 , we recognise the left-hand member as the $\log$ survival ratio. $A$, the slope, is a constant. The linear relationship between log survival ratio and $E$ indicates that one quantum 'kills', that is, activates one unit. In other words, the quantum absorbing unit does photosynthetic work after a single absorption.

(3) The slope $A$ measures the 'blackness' of the absorbing entity. Because $A$ is determined by the work done, that is, by the number of effective absorptions, we may call it (1) the functional molecular absorption coefficient of chlorophyll, or (2) the absorption coefficient of one photosynthetic absorption unit. The value of $A$ was $9.7 \times 10^{-14}(\mathrm{~cm} .8)$ quanta). This is 360 times greater than the maximum value $(6200-7000 \mathrm{~A}$.) of the molecular absorption coefficient of chlorophyll dissolved in ether. Therefore, since the total absorption by intact Chlorella cells and by an extract of these cells is approximately equal $^{6}$, it appears that more than 360 chlorophyll molecules comprise an absorption unit within the plant. The unit, used in this sense, means a mechanism which makes available the energy of an absorbed quantum; it is not assumed that this is a rigid structure.

Previously, we had found 2,000 to be the minimum number of chlorophyll molecules present per molecule of carbon dioxide reduced per flash? quanta are necessary to reduce one molecule of carbon dioxide, this corresponds to an absorption unit of 500 .

Experimental Zoological Institute,

Henry I. KoHN. Drottninggatan-116a, Stockholm. Feb. 27.

1H. Gaffron and K. Wohl, Naturwiss, 24, 81 and 103 (1936). 2 R. Emerson and W. A. Arnold, J. Gen. Physiol., 15, 391 (1932). 3 O. Warburg and E. Negelein, Z. phys. Chem., 106, 191 (1923). - J. A. Crowther, Proc. Roy. Soc., B , 100, 390 (1926)

F. A. Crowther, Proc. Roy. Soc., B, 100,390

H. I. Kohn, J. Gen. Physiol., 19, 23 (1935).

H. I. Kohn, J. Gen. Physiol., 19, 23 (1935) W. A. Arnold and H. I. Kohn, ibid., 18, 109 (1934),

\section{Diamagnetic Susceptibility of Heavy Water}

Mr. F. E. Hoare has directed attention ${ }^{1}$ to the divergence in the mass susceptibility values for heavy water found by himself, Cabrera and Fahlenbrach, and Selwood and Frost. The mass susceptibility of deuterium oxide having been determined in this laboratory in connexion with other work, it may be of interest, in view of Hoare's remarks, to record our value for comparison with the values already published.

We find, using a modified Gouy balance ${ }^{2}$ which has been calibrated with a number of highly purified organic liquids (benzene, acetone, chloroform) and inorganic salts (sodium chloride, copper sulphate, nickel sulphate and nickel ammonium sulphate) and with pure distilled water, that the mass susceptibility of heavy water is $0.637 \pm 0.001$ at $20^{\circ}$. Two specimens of heavy water of density $1 \cdot 1049$ and containing $99 \cdot 2$ per cent deuterium oxide were used. It was measured in two different containers, one of which held $4 \cdot 0810 \pm 0 \cdot 0014 \mathrm{gm}$. and the other $3 \cdot 7760 \pm$ $0.0025 \mathrm{gm}$.; the mean mass susceptibility in the two tubes being respectively $0 \cdot 639 \pm 0.001$ and $0 \cdot 638 \pm 0.001$ units of $10^{-6}$.

These values when corrected for 0.8 per cent of ordinary water, which is taken as having a mass susceptibility of 0.720 units of $10^{-6}$, give a value for deuterium oxide of $0 \cdot 637 \pm 0.001$ and a molecular susceptibility of $12 \cdot 76$ units of $10^{-6}$ on the assumption that $\mathrm{D}_{2} \mathrm{O}$ has a molecular weight $20 \cdot 027$. This value is in complete agreement with that of Cabrera and Fahlenbrach.

\section{Bedford College, \\ London.} V. C. G. TrEW.

March 25.

1 NATURE, 137, 497 (1936).

Trans. Faraday Soc., Dec. 1933. 